was $180 \cdot 7^{\circ}\left(\mathrm{SD} \pm 5 \cdot 2^{\circ}\right.$, range $\left.165-189^{\circ}\right)$ and $194.5^{\circ}$ (SD $\pm 7 \cdot 5^{\circ}$, range $178-205^{\circ}$ ) respectively. There were highly significant differences between the mean hyponychial angles of the two groups $(P<0.001)$.

16 of the 19 patients had profile angles which exceeded the normal range, while 3 with clinical clubbing of the middle and/or ring finger, but not of the index finger, had normal angles. There was good correlation between the clinical diagnosis of clubbing and assessment by the shadowgram.

\section{Discussion}

Clinical assessment of finger clubbing is subjective and unreliable (Pyke, 1954; Carroll, 1972) but it is very useful as an indicator of underlying disease. The shadowgraph is a cheap and simple technique which allows serial measurements of the profile and hyponychial angles to be made speedily and without discomfort. There is excellent correlation between the clinical diagnosis of clubbing and assessment by this technique. The hyponychial angle appears to correlate more closely with the clinical diagnosis than the profile angle, as was found by Regan et al. (1967) and Bentley et al. (1976).

\section{References}

Bentley, D., Moore, A., and Shwachman, H. (1976). Finger clubbing: a quantitative survey by analysis of the shadowgraph. Lancet, 2, 164-167.

Carroll, D. G., Jr (1972). Curvature of the nails, clubbing of the fingers, and hypertrophic pulmonary osteoarthropathy. Transactions of the American Clinical and Climatological Association, 83, 198-208.

Lancet (1975). Editorial: Finger clubbing. Lancet, 1, 1285.

Pyke, D. A. (1954). Finger clubbing. Validity as a physical sign. Lancet, 2, 352-354.

Regan, G. M., Tagg, B., and Thomson, M. L. (1967). Subjective assessment and objective measurement of finger clubbing. Lancet, 1, 530-532.

Correspondence to Professor D. Sinniah.

\title{
Fatal bleeding from gastric ulceration during first day of life-possible association with social stress
}

\author{
R. J. PUGH, R. W. NEWTON, AND D. M. PIERCY \\ Departments of Paediatrics and Pathology, Hull Royal Infirmary, North Humberside
}

SUMMARY Death from haemorrhage is described in a 21-hour-old baby boy with acute gastric ulceration. Particular note is made of the very high level of psychosocial maternal stress during the last trimester of pregnancy. A causal relationship of this stress and the peptic ulceration is suggested, with gastrin as the mediator.

A 17-year-old primigravida was admitted in labour after an uncomplicated pregnancy and monitored cardio-tocographically without causing concern. The first stage of labour lasted 5 hours and the second 20 minutes, producing a healthy baby boy at term, weighing $2.73 \mathrm{~kg}$, by a spontaneous normal vaginal delivery. The Apgar score was 4 at one minute and 8 at five minutes. No special resuscitative procedures were needed, no nasogastric tube was passed, and vitamin K $1 \mathrm{mg}$ was administered intramuscularly.

The baby had normal infant care alongside its mother, taking $5 \%$ dextrose solution eagerly by bottle until, at age 20 hours, fresh blood was vomited and shown by Apt's test to be of infant origin. Clinical examination then showed a vigorous baby with no purpura, bruising, or haemangiomata. There was no family history of bleeding disorder, and no aspirin or similar drugs had been administered to the mother at the relevant time. The mother was in good health. A venous blood sample on admission at 20 hours showed the baby to have a haemoglobin of $14 \cdot 2 \mathrm{~g} / \mathrm{dl}$, a platelet count of $160 \times 10^{9} / 1(160000 /$ $\mathrm{mm}^{3}$ ), and no abnormality in the prothrombin, partial thromboplastin, or thrombin times. A similar coagulation screen of the mother's blood was also normal.

During the next half-hour further fresh blood was vomited repeatedly, resulting in a critical degree of shock with apathy and loss of awareness. A catheter introduced into the inferior vena cava via the umbilical vein recorded a low central venous pressure and $75 \mathrm{ml}$ of O-negative whole blood was transfused rapidly with only fleeting benefit. Death supervened at 21 hours, only one hour after the first haematemesis.

Necropsy showed the source of bleeding to be 3 areas of gastric ulceration: 2 on the posterior wall and one on the greater curvature (Figure). Histological examination showed that they were of the acute peptic 




Figure Two peptic ulcers on the posterior gastric wall (note remnant blood clot in upper ulcer).

type with endarteritic changes in the smaller, most distal, ulcer.

After this tragic death a discreet social inquiry found that the pregnancy, and particularly the last trimester, had been exceptionally stressful and unhappy. At the time of conception the mother was only 16 , unmarried, and working in a factory as a hosiery examiner. She married the equally young father to comply with parental wishes, but lived with him for only 2 weeks before returning to her parents' home to escape from drunken physical assaults. Subsequently her husband made frequent visits to her parents' home in ill-conceived attempts at reconciliation, causing great distress, panic, and revulsion. One such visit shortly before labour began culminated in a brick being thrown at her through the living-room window and the intervention of the police.

\section{Comment}

The occurrence of peptic ulceration in the newborn infant, particularly in boys, has often been described.
Presentation is usually with haematemesis or perforation (Bird et al., 1941; Smith, 1975). We know that stress increases the incidence of peptic ulceration in adults (Rose, 1978) and the possibility exists that greatly increased maternal stress late in the pregnancy may have a similar association with gastric ulceration in the newly born-presumably mediated by a maternal hormone crossing the placenta.

When gastrin is administered to the experimental dog late in pregnancy there is an increased incidence of pyloric stenosis, in some cases associated with pyloro-duodenal ulceration in the offspring (Dodge, 1970; Karim et al., 1974). Dodge (1972) and Revill and Dodge (1978) drew attention to the higher incidence of maternal stress in the latter part of pregnancy in babies with pyloric stenosis and suggested that gastrin is the biochemical mediator.

We believe our patient to be the first in whom gastric ulceration with bleeding in the first day of life has been tentatively identified with maternal stress as cause and effect. It is possible that in this case gastrin was the biochemical mediator of the stress and the cause of gastric ulceration. 


\section{Conclusion}

A careful social history may be particularly relevant in high gastrointestinal bleeding or perforation in the early newborn period. Conversely, such pregnancies should be regarded as particularly at risk and managed accordingly.

\section{References}

Bird, C. E., Limper, M. A., and Mayer, J. M. (1941). Surgery in peptic ulceration of stomach and duodenum in infants and children. Annals of Surgery, 114, 526-542.

Dodge, J. A. (1970). Production of duodenal ulcers and hypertrophic pyloric stenosis by administration of pentagastrin to pregnant and newborn dogs. Nature, 225, 284-285.
Dodge, J. A. (1972). Psychosomatic aspects of infantile pyloric stenosis. Journal of Psychosomatic Research, 16, 1-5.

Karim, A. A., Morrison, J. E., and Parks, T. G. (1974). The role of pentagastrin in the production of canine hypertrophic pyloric stenosis and pyloroduodenal ulceration (abstract). British Journal of Surgery, 61, 327.

Revill, S. I., and Dodge, J. A. (1978). Psychological determinants of infantile pyloric stenosis. Archives of Disease in Childhood, 53, 66-68.

Rose, G. (1978). Aetiology and prevention. In Medicine, third series, part 1, pp. 5-6. Medical Education (International) : Oxford.

Smith, C. W., Jr (1975). Massive haemorrhage from multiple gastric ulcers in the newborn. A case report-with recent literature review. North Carolina Medical Journal, 36, 97-99.

Correspondence to Dr R. J. Pugh, Department of Paediatrics, Hull Royal Infirmary, Anlaby Road, Hull HU3 2JZ.

\section{Hepatomegaly due to self-induced hyperinsulinism}

\section{JACK ASHEROV, MARC MIMOUNI, ITZHAK VARSANO, ERNESTO LUBIN, AND ZVI LARON \\ Institute of Paediatric and Adolescent Endocrinology, and Department of Nuclear Medicine, Beilinson Medical Centre, Petah Tikva, and the Sackler School of Medicine, Tel Aviv University, Israel}

SUMMARY Repeated hypoglycaemic attacks, associated with transient hepatomegaly, in a 12-year-old insulin-dependent diabetic girl continued despite reduction in dose and, later, complete discontinuance of insulin. The attacks ceased while she was in hospital, necessitating reinstitution of insulin. The hepatomegaly resolved when surreptitious additional insulin injections were discovered and stopped. Hepatomegaly in diabetics should arouse suspicion of over dosage with insulin.

Hepatomegaly associated with diabetic hypoglycaemia was well known before long-acting insulin became available (Madison, 1969), but it has seldom been encountered recently (Rosenbloom and Giordano, 1977). We present a 12-year-old insulindependent diabetic with transient hepatomegaly associated with hypoglycaemia induced by surreptitious additional insulin injections, and discuss the role of over dosage with insulin in inducing hepatomegaly.

\section{Case report}

We have followed-up a 12-year-old girl since age 5 when insulin-dependent diabetes was diagnosed and treatment initiated. For 7 years control was good, but then frequent hypoglycaemic attacks of moderate severity were reported. The hypoglycaemic attacks persisted despite reduction in insulin dose and, later, its complete discontinuance. Marked hepatomegaly was noted, and the girl was admitted for investigation.

She was then a lean, normotensive, healthy looking child with a firm, tender liver palpable $12 \mathrm{~cm}$ below the costal margin. SGOT $138 \mathrm{IU} / \mathrm{ml}$ (normal <40), LDH $156 \mathrm{IU} / \mathrm{ml}$ (normal <235), alkaline phosphatase $181 \mathrm{IU} / \mathrm{ml}$ (normal for age), acid phosphatase $1.5 \mathrm{U} / \mathrm{ml}$ (normal 0-1), bromosulphalein retention $2.4 \%$ after $45 \mathrm{~min}$, serum ammonia $57 \mu \mathrm{g} / 100 \mathrm{ml}$ (normal <85), antitrypsin $88 \mathrm{mg} / 100 \mathrm{ml}(0.88 \mathrm{~g} / \mathrm{l}) \alpha$-fetoprotein negative; normal bilirubin, electrolytes, and copper ceruloplasmin. Australian antigen tests, endocrinological studies including evaluation of pituitary and adrenal, and haematological study, including bone marrow aspiration, were all normal. Scan showed diffuse liver enlargement and a normal spleen (Fig. 1a).

After 3 days without treatment, the fasting serum insulin was $5 \cdot 2 \mu \mathrm{U} / \mathrm{ml}$. Because of hyperglycaemia (up to $405 \mathrm{mg} / \mathrm{dl}$ ) and glycosuria (up to $4 \%$ ), the insulin was restarted. The hypoglycaemic attacks then ceased, the liver size decreased to $6 \mathrm{~cm}$ below the costal margin, and she was discharged.

After 5 months of good control in which only the edge of the liver remained palpable (Fig. 1b) the hypoglycaemia and hepatomegaly recurred. Because of the history and laboratory findings, we suspected overinsulinism. The mother then discovered that the girl surreptitiously injected additional insulin, probably to attract notice by provoking hypoglycaemic spells. 